Article

\title{
Ecological Corridors Analysis Based on MSPA and MCR Model-A Case Study of the Tomur World Natural Heritage Region
}

\author{
Hui Ye ${ }^{1,2}$, Zhaoping Yang ${ }^{1, *}$ and Xiaoliang $\mathrm{Xu}^{1}$ \\ 1 State Key Laboratory of Desert and Oasis Ecology, Xinjiang Institute of Ecology and Geography, Chinese \\ Academy of Science, Urumqi 830011, China; yehui16@mails.ucas.edu.cn (H.Y.); xuxl@ms.xjb.ac.cn (X.X.) \\ 2 Department of Resources and Environmental Sciences, University of Chinese Academy of Sciences, \\ Beijing 100049, China \\ * Correspondence: yangzp@ms.xjb.ac.cn; Tel.: +86-991-788-5472
}

Received: 4 December 2019; Accepted: 26 January 2020; Published: 28 January 2020

\begin{abstract}
The rapid urbanization process, accompanied by the transformation of high-intensive land development and land use, constantly encroaches on habitat patches, making them increasingly fragmented and isolated, which directly influences the regional landscape pattern and sustainable development. Taking the Tomur World Natural Heritage region as the study area, the morphological spatial pattern analysis (MSPA) method and landscape index method were used to extract the ecological source areas of great significance to the construction of ecological corridors. Then, using the minimum cumulative resistance model $(M C R)$, the comprehensive resistance surface was constructed and the potential corridors were generated by the minimum cost path method. Finally, according to the gravity model, the important corridors of the study area were designed. Results showed that the MSPA method and MCR model can be used in combination to identify the potential ecological corridors in the study area and clarify the priority of landscape element protection in the study area, which can provide guidance to construct the ecological network and provide reference for other regions as well.
\end{abstract}

Keywords: MSPA; MCR; ecological corridors; landscape connectivity; Tomur World Natural Heritage region

\section{Introduction}

The rapid urbanization process, accompanied by the transformation of high-intensive land development and land use, constantly encroaches on habitat patches, making them increasingly fragmented and isolated, which directly influences the regional landscape pattern and sustainable development. Landscape fragmentation reduces the patch area of internal habitat, hinders the operating and regulating ability of normal landscape ecological processes, and damages ecological corridors [1,2]. Landscape connectivity is reduced, which blocks the migration of species and the spread of the material energy and impairs the health of ecosystem integrity, leading to changes in ecosystem services [3]. Therefore, connecting isolated broken ecological patches and stepping stones through potential corridors within the borders can improve the impact of fragmented landscapes on biodiversity and the connectivity of landscape and promote the exchanges of genetic material and species between patches, which would effectively improve the service functions of natural ecosystems and have an important ecological significance [4,5].

Since the 1990s, many scholars have tried to build and analyze ecological corridors at different spatial scales from the perspective of landscape ecology, and many models and methods have been produced [6-8]. Among them, the most common methods include the minimum cumulative resistance 
model (MCR), the graph theory method, and current theory. The MCR model, which is based on GIS technology, can calculate the cost incurred by species from ecological sources of different landscape and land use types to simulate the path of least cumulative resistance, so as to build an ecological corridor. To date, it has been widely used in relevant research fields. The MCR model can comprehensively consider the terrain, landform, environment, human disturbance, and other factors in the region and has the advantages of a small amount of data and map expression of results $[9,10]$. The model is usually combined with the gravity model, mapping theory, and connection index to quantitatively evaluate and optimize the ecological corridors [11]. The selection of an ecological source is key to the establishment of ecological corridors through the MCR model. However, in the current relevant studies, the selection of an ecological source is somewhat subjective and ignores the connectivity role of patches in the landscape [12,13].

In recent years, a morphological spatial pattern analysis method (MSPA) focusing on measuring structural connectivity has been introduced into the identification of ecological sources. Emphasizing on structural connection, this method only depends on land use data [14-16]. After the classification of land use to extract forest, wetland, water, and other natural ecological elements as a foreground and other land use types as the background, a series of image processing methods are used to divide the foreground into seven non-overlapping categories (namely, core, bridge, ring, edge, branch, loop, islet, and performation), and then landscape types that are important for maintaining connectivity are identified, which increases the scientific nature of ecological source and ecological corridor selection $[17,18]$.

The core of ecological corridors is considered to include the connection of organisms with landscape [14]. Further, ecological corridors provide ecological services such as saving water, purifying pollutants, and reducing the heat island effect [19]. Ecological corridors facilitate the migration of animals and plants between habitat patches, thus enhancing connectivity between isolated populations [20]. It is suggested to use corridors to connect isolated habitat patches to mitigate the negative impact of habitat fragmentation [21].

There are several studies on green infrastructure projects sharing the common goal of sustainable land management planning. The GI was related to the identification and mapping of ecological networks [22]. Benedict and McMahon considered that the two primary components of ecological networks are hubs and links [23]. Hubs are areas of natural vegetation, other open space, or areas of known ecological value, and links are the corridors that connect the hubs to each other. The spatial patterns of GI were identified and quantified in heterogeneous urban areas; for example, bridges are considered as connectivity for species dispersal and movement [24].

Landscape connectivity refers to the extent to which the landscape facilitates or impedes the flow of existing resources [25]. Ecological assessments of landscape use need to consider the ability of species to migrate in nonhabitats from the perspective of functional connectivity [26]. Functional connectivity is ensured not only when existing habitat units are physically adjacent, but also when a permeable matrix, a series of stepping stones, or other connecting elements allow a particular organism to move between habitats that may be physically distant [27]. Lack of landscape connectivity and subsequent isolation of habitat patches can interfere with ecological processes such as pollination, seed transmission, gene flow, and wildlife migration and reproduction [28-30].

The methods of MSPA and MCR to analyze ecological corridors are used more in the middle and east of China, but less in the northwest. Additionally, there are some studies on urban ecological networks, and there is no research on ecological corridors of a certain world natural heritage site at present in China. The selection of an ecological source is the key of the MCR model. Today, most studies directly select forest parks or nature reserves with a good ecological service value as an ecological source, with large subjective interference, ignoring the connectivity role of patches in the landscape. MSPA is used in this study to identify the important habitat patches and corridors which play an important role in landscape connectivity at the pixel level. 
Based on the MSPA method, this paper takes the Tomur World Natural Heritage site as the research area and identifies and extracts the landscape types of the core areas with the best ecological functions in the study area. According to the integral index of connectivity (IIC), the probability of connectivity $(P C)$, and the delta of $P C\left(d_{P C}\right)$ in the landscape index, the patches in the core area would be quantitatively evaluated so as to select the ecological source in the study area. Ecological corridors are generated through the $M C R$ model using the minimum path method, and the relative importance of corridors is determined based on the gravity model. Then, the patches with good intermediary function are identified as stepping stones through the intermediary centrality, and the potential corridor in the research area is planned, so as to provide a reference for constructing the regional landscape ecological pattern with a complete structure.

\section{Materials and Methods}

\subsection{Study Area}

The Tomur region includes the counties of Zhaosu, Wensu, and Baicheng in Xinjiang, China. The highest peak of the mountain of Tianshan, located in the three counties, is one of the constituent areas of Xinjiang Tianshan World Natural Heritage. East-west mountain systems such as Halketawu, Khantengri, and Tomur cross the study area and divide it into the south and the north. The geographic coordinates are $79^{\circ} 27^{\prime} 10^{\prime \prime} \sim 83^{\circ} 04^{\prime} 20^{\prime \prime} \mathrm{E}, 40^{\circ} 48^{\prime} 57^{\prime \prime} \sim 43^{\circ} 22^{\prime} 05^{\prime \prime} \mathrm{N}$, with a total area of $40,884.07 \mathrm{~km}^{2}$ (Figure 1A). The study area belongs to the temperate continental climate, and the climate is significantly affected by the terrain. The north slope is wet, while the south slope is dry. Precipitation is concentrated in the summer and winter, and precipitation in the north slope is significantly higher than that in the south slope. The difference of natural geographical environment, such as the climate of the south and north slope, forms a different vertical natural landscape belt. There are seven large rivers on the south and north slopes, which are mainly fed by melting water from snow and ice [31].

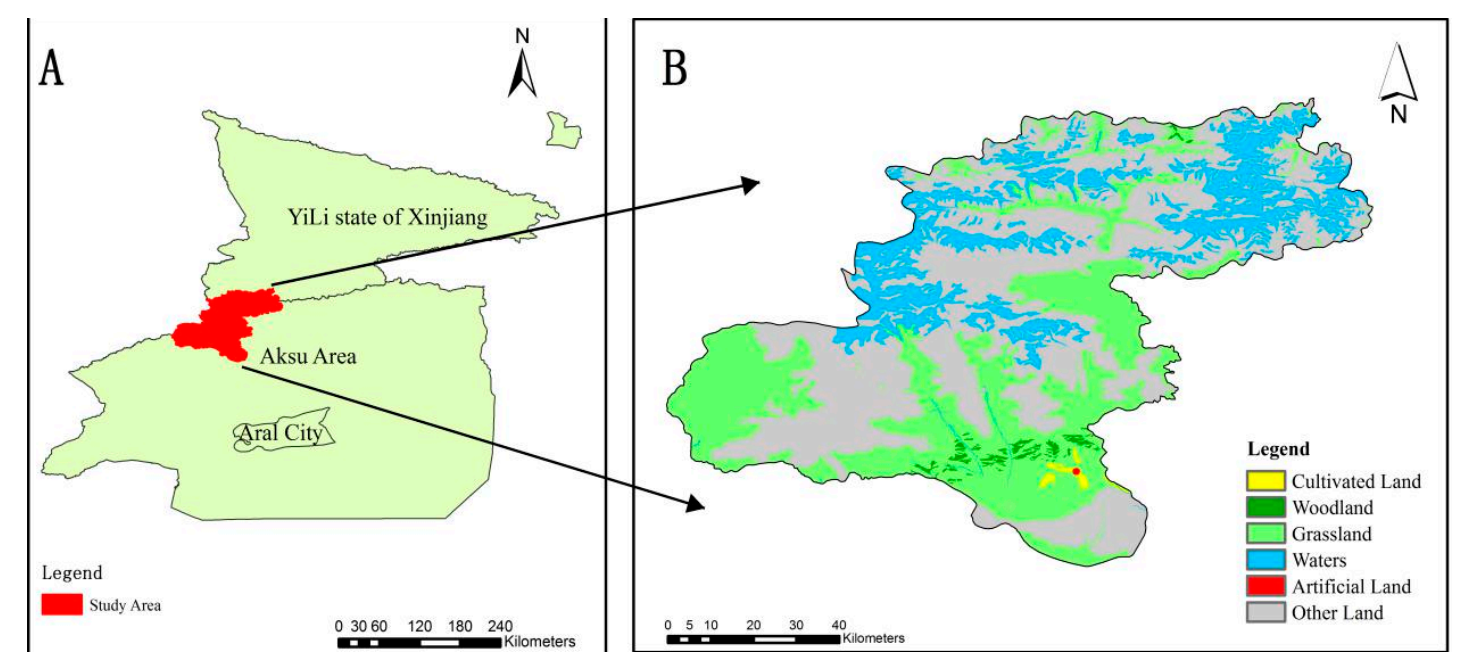

Figure 1. (A) Location of the study area and (B) land use. Drawn by the first author.

The vegetation distribution in the study area has obvious vertical differentiation characteristics. In the south, a complete set of seven vertical natural belts have developed, with the altitude from low to high successively being the warm temperate desert belt, temperate desert steppe belt, mountain steppe belt, subalpine meadow belt, alpine meadow belt, alpine cushion vegetation belt, and snow and ice belt. In the north, the vegetation coverage is high, and the soil is mainly chestnut and chernozem. Human activities mainly include grazing, tourism, and mining. Due to the lack of reasonable protection and management measures, unreasonable human activities lead to vegetation degradation and soil erosion. In the south, there is a large proportion of saline-alkali land, bare rock, fertile land, and desert, with moisture soil, meadow soil, saline soil, sand soil, and brown desert soil. The loose soil 
structure and poor consolidation strength lead to low vegetation coverage and distribution of shallows, and vegetation degradation and desertification are easy to occur, encountering mudslides, heavy rain, and other natural disasters [32].

\subsection{Data Resource}

The main data adopted in this study are the 2015 land use data of Tomur region, the DEM (Digital Elevation Model) data of the Tomur region (http://www.gscloud.cn/), and the road network data of the Tomur region (https://www.openstreetmap.org/). The digital maps were rectified by ground control points to project into WGS_1984_UTM_Zone_44N coordinates. ENVI (The Environment for Visualizing Images, manufactured by American company Exelis Visual Information Solutions) software, which is the ideal software for the visualization, analysis, and presentation of all types of digital imagery (https://envi.software.informer.com/), was used to further enhance remote sensing image data in the study area, so as to improve image data quality and prepare for the next step of data processing. Then, ENVI software was used to monitor and classify the image data in the study area based on visual interpretation, and the Kappa value was 0.84 after an accuracy test of the classification results, which is of very good agreement [33].

The land use classification map of the study area with a grid size of $30 \times 30 \mathrm{~m}$ was finally obtained (Figure 1B). According to the actual situation and research purpose of the research area, the land use types in the research area are divided into six types: cultivated land, woodland, grassland, waters, artificial land, and other land. The original resolution of the data is $30 \mathrm{~m}$. All data were used in raster format with the same spatial resolution (i.e., grid cell size corresponding to $1000 \mathrm{~m}$ in each raster).

\subsection{Methods}

\subsubsection{Landscape Pattern Analysis Based on the MSPA Method}

The MSPA classification routine starts by identifying core areas, based on user-defined rules for defining connectivity and edge width [34]. Different from the traditional method in which the nature reserves or forest parks were selected directly as the patches or corridors, MSPA is used to identify the important habitat patches and corridors which play an important role in landscape connectivity at the pixel level [35].

After the classification of land use, woodland, grassland, and waters are extracted to be the foreground, and artificial land and other land as the background, a series of image processing methods are used to divide the foreground into seven non-overlapping categories (namely, core, bridge, edge, branch, loop, islet and performation) (Table 1), and then categories that are important for maintaining connectivity are identified, which increases the scientific nature of the ecological source and ecological corridor selection [36,37].

Then, using the Guidos Toolbox [38], MSPA analysis was conducted on raster-grid data, core patches were obtained through erosion calculation, and the other 6 categories were obtained through a series of mathematical operations. Thus, 7 categories with different functions can be obtained, and the analysis of the results can be conducted. 
Table 1. Morphological spatial pattern analysis (MSPA) categories and ecological implications.

\begin{tabular}{|c|c|}
\hline MSPA Categories & Ecological Implication \\
\hline Core & $\begin{array}{c}\text { It can be used as the "source" of a variety of ecological processes, most of which are forest parks with large patch areas and large forest } \\
\text { farms, etc., which are of great significance for species reproduction and biodiversity protection. }\end{array}$ \\
\hline Bridge & $\begin{array}{l}\text { The narrow and long areas connecting the patches of different core areas, and which have the characteristics of ecological corridors, } \\
\text { which are mostly green belts, which are conducive to the migration of species and the connection of landscape within the territory. }\end{array}$ \\
\hline Edge & $\begin{array}{l}\text { The transition zone between the marginal zone of the core area and the peripheral nongreen landscape area, which can reduce the impact } \\
\text { brought by the external environment and human disturbance, usually the peripheral forest zone of forest parks and large forest farms. }\end{array}$ \\
\hline Branch & $\begin{array}{c}\text { Only one end is connected to the main patch, mainly an extension of the green space, which is the channel for species diffusion and } \\
\text { energy exchange with the peripheral landscape. }\end{array}$ \\
\hline Loop & $\begin{array}{l}\text { The internal channel of material and energy exchange in the same core area is the shortcut of material and energy exchange in } \\
\text { the core area. }\end{array}$ \\
\hline Islet & $\begin{array}{l}\text { Small patches, which are independent of each other and have low connectivity, are less likely to communicate with other patches in terms } \\
\text { of material and energy, and are mostly small green Spaces in urban or rural areas. }\end{array}$ \\
\hline Perforation & As a transition region, the edge effect also exists between the core patch and its inner non-green space. \\
\hline
\end{tabular}

\subsubsection{Evaluation of Landscape Connectivity in the Study Area}

The level of landscape connectivity in a region can quantitatively characterize whether a certain landscape type is suitable for species exchange and migration, which is of great significance for biodiversity protection and ecosystem balance [39].

At present, in the aspect of landscape connectivity evaluation, the integral index of connectivity (IIC, Equation (1)), the probability of connectivity (PC, Equation (2)), and the delta of $P C$ ( $d_{P C}$, Equation (3)) are commonly used as the important indicators of landscape pattern and function, which can reflect well the degree of connection between core patches in the regional level [40].

$$
\begin{gathered}
I I C=\frac{\sum_{i=1}^{n} \sum_{j=1}^{n} \frac{a_{i} \cdot a_{j}}{1+n l_{i j}}}{A_{L}^{2}} \\
P C=\frac{\sum_{i=1}^{n} \sum_{j=1}^{n} a_{i} \cdot a_{j} \cdot P_{i j}^{*}}{A_{L}^{2}} \\
d_{P C}=\frac{P C-P C_{\text {remove }}}{P C} \cdot 100 \%
\end{gathered}
$$

where $\mathrm{n}$ represents the total number of patches in the region; $a_{i}$ and $a_{j}$ are the areas of patch $i$ and $j$, respectively; $n l_{i j}$ represents the number of connections between patch $i$ and patch $j ; P^{*}{ }_{i j}$ is the maximum product of all path probabilities between patch $i$ and patch $j ; A_{L}$ is the total landscape area of the study area; and IIC represents the integral index of connectivity. Please note that $0 \leq I I C \leq 1$, and if IIC $=0$, there is no connection between habitat patches; whereas if IIC $=1$, the whole landscape is a habitat patch. $P C$ represents the possible connectivity index of a patch in the landscape of the study area; $0 \leq P C \leq 1$, the larger the $P C$ value is, the higher the connectivity degree of the patch is; $d_{P C}$ is the change (in \%) of the connectivity index after removing one patch.

Conefor software was used to evaluate the landscape connectivity of patches in the core areas in the study area through the IIC, $P C$, and $d_{P C}$ landscape index, and the 10 patches in the core areas with a $d_{P C}$ value greater than 5 were regarded as the source of biological species development and proliferation [41].

\subsubsection{Ecological Corridor Construction Based on the MCR Model}

The minimum cumulative resistance model $(M C R)$ is characterized by simplicity of construction, extensibility of elements, and universality of application. By calculating the minimum cumulative resistance distance between source and the target to determine the path, it can better reflect the 
movement possibility and tendency of material energy and biological species in landscape patches [42]. After modification by several experts, the formula of $M C R$ model is as follows:

$$
M C R=f_{\min } \sum_{j=n}^{i=m}\left(D_{i j} \times R_{i}\right)
$$

where $D_{i j}$ represents the spatial distance from the source point $j$ to the space unit $i$ and $R_{i}$ represents the resistance coefficient of space unit $i$. The key to the establishment of the MCR model is the selection of the source and the construction of the resistance surface system. The core process is the competitive diffusion process of the source to the surrounding space units under the resistance surface system [43]. In this paper, combined with the analysis and evaluation results of MSPA and landscape connectivity, 10 sources of ecological processes were selected according to the $d_{P C}$ value of patches in the core area, and resistance factors such as elevation, slope, land type, distance from railway, and distance from other roads were selected to construct the comprehensive resistance surface through the "comprehensive weighted index and method".

With reference to relevant research results, the AHP (analytical hierarchy process) method, which is achieved through a pairwise comparison method between the elements for each hierarchical level [30], was used to determine the resistance score and weight of each factor, and a resistance system was constructed, which was divided into 5 resistance scores. The higher the score, the greater the resistance of the diffusion process of biological species [44]. A grid unit size of $30 \times 30 \mathrm{~m}$ was adopted, and the integrated resistance surface was obtained by the grid calculator as the cost data of the MCR model.

Then, using the ArcGIS software platform and the cost distance module in distance, the minimum cumulative cost distance between each pixel and the nearest unit on the cost surface was calculated using the ecological source and comprehensive resistance surface. Then, the cost path module in distance was used to calculate the minimum cost path from the source to the target patch; thus, 45 potential corridors in the study area were generated. The interaction matrix between patches of 10 ecological source areas was calculated using the gravity model. The interaction intensity between patches of different source areas was evaluated in a quantitative way so that the relative importance of potential corridors in the region could be judged more scientifically.

The gravity model formula is as follows:

$$
G_{i j}=\frac{N_{i} N_{j}}{D_{i j}^{2}}=\frac{\left[\frac{1}{P_{i}} \times \operatorname{In}\left(s_{i}\right)\right]\left[\frac{1}{P_{j}} \times \operatorname{In}\left(s_{j}\right)\right]}{\left(\frac{L_{i j}}{L_{\max }}\right)^{2}}=\frac{L_{\max }^{2} \operatorname{In}\left(s_{i} s_{j}\right)}{L_{i j}^{2} P_{i} P_{j}}
$$

where $G_{i j}$ is the interaction intensity between patch $i$ and patch $j$, and $N_{i}$ and $N_{j}$ are the weight coefficients of patch $i$ and patch $j$, respectively. $D_{i j}$ is the standardized resistance value of potential corridors between patch $i$ and patch $j . P_{i}$ is the overall resistance value of patch $i ; S_{i}$ is the area of patch $i$; and $L_{i j}$ is the cumulative resistance value of potential corridors between patch $i$ and patch $j . L_{\max }$ is the maximum resistance value of all corridors in the study area.

In summary, the methodology steps are as follows (Figure 2). 


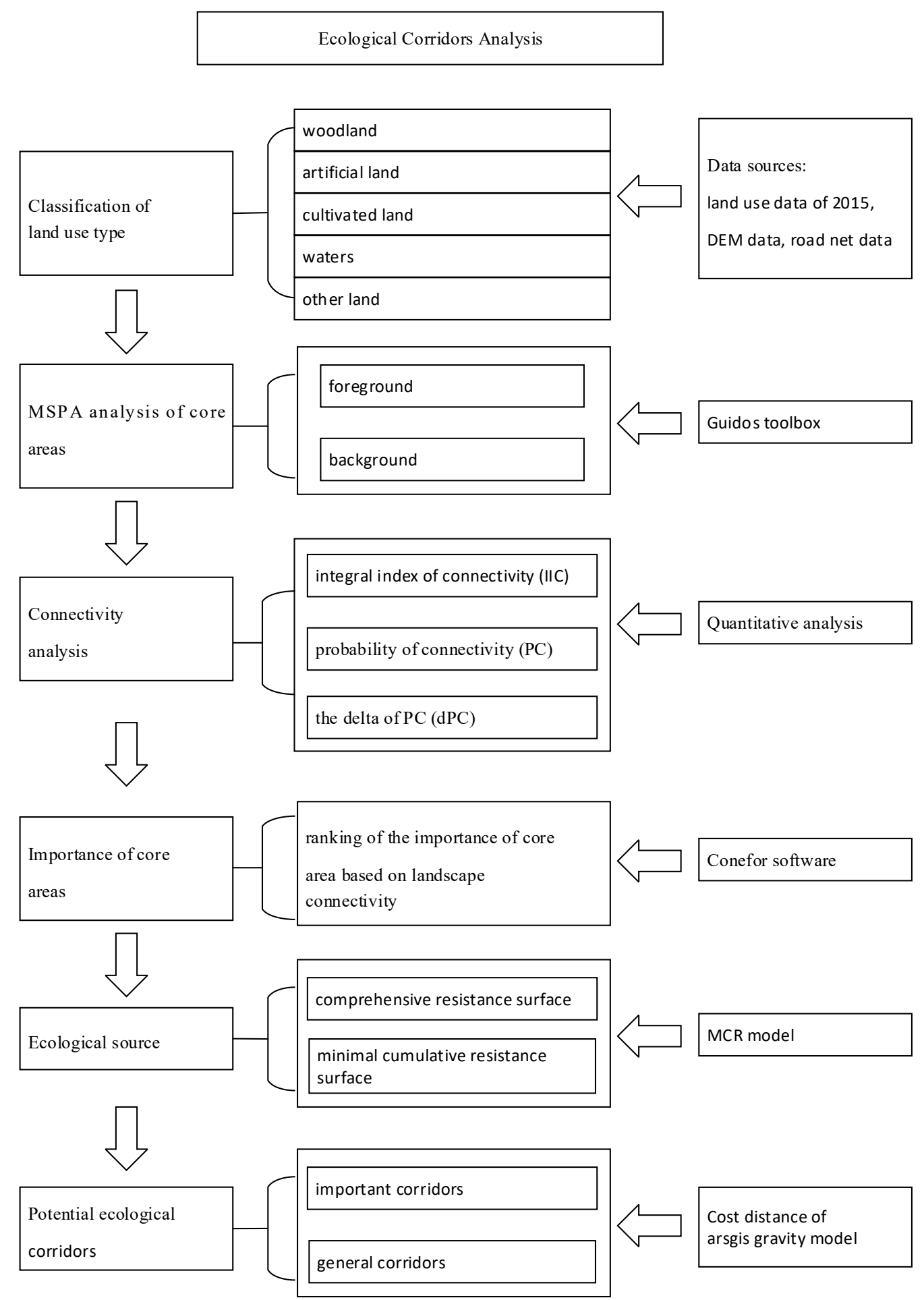

Figure 2. Methodology steps of ecological corridors analysis. Drawn by the first author.

\section{Results}

\subsection{Landscape Pattern Analysis of the Tomur Region Based on MSPA}

Using the Guidos Toolbox, MSPA analysis was conducted on raster-grid data, core patches were obtained through corrosion calculation, and the remaining six types of landscapes were obtained through a series of mathematical operations such as expansion and reconstruction and skeleton 
extraction. Thus, seven types of landscapes with different functional types can be obtained (Figure 3), and their analysis results can be counted (Table 2).

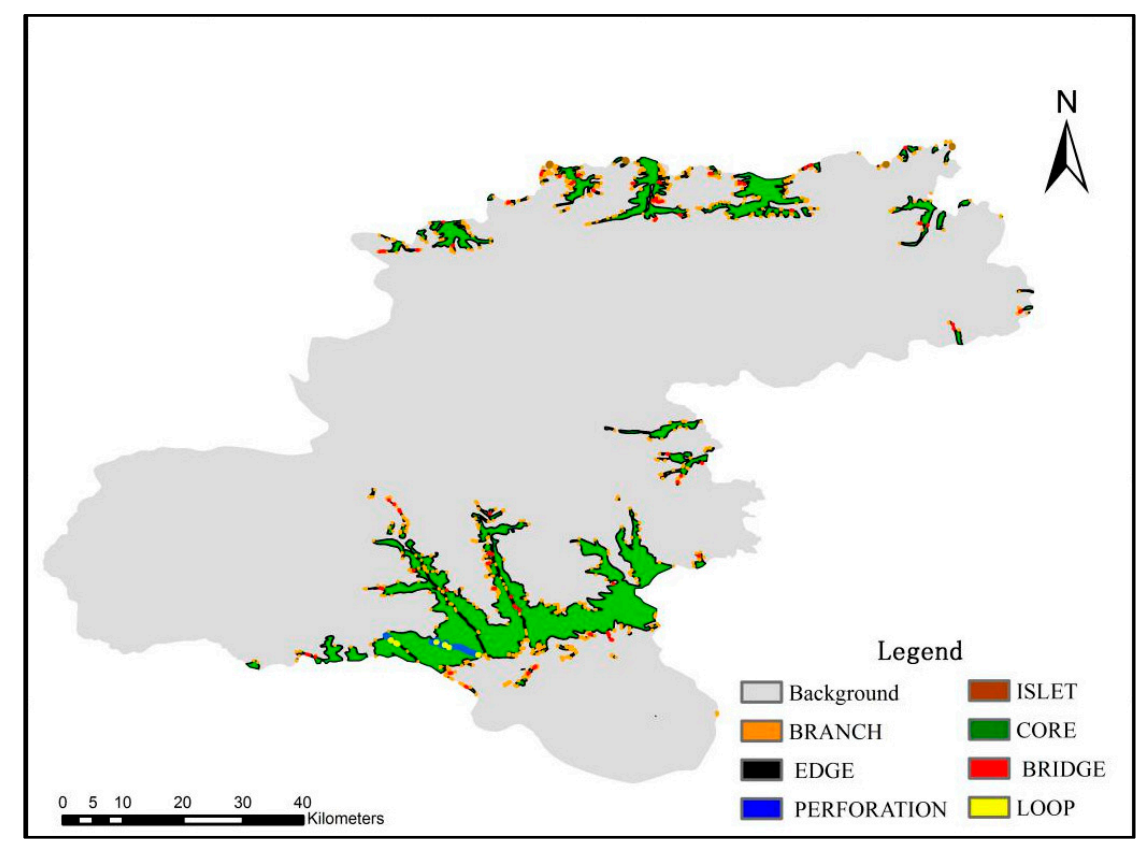

Figure 3. Analysis results of MSPA. Drawn by the first author.

Table 2. Classification statistics table of MSPA.

\begin{tabular}{cccc}
\hline Landscape Type & Area(ha) & $\begin{array}{c}\text { Accounting for a Total Area of } \\
\text { Woodland Landscape (\%) }\end{array}$ & $\begin{array}{c}\text { Accounting for a Total } \\
\text { Area of (\%) }\end{array}$ \\
\hline Core Area & $40,721.70$ & 84.27 & 6.98 \\
\hline Bridge & 62.81 & 0.13 & 0.01 \\
\hline Edge & 6968.16 & 14.42 & 1.19 \\
\hline Branch & 420.40 & 0.87 & 0.07 \\
\hline Loop & 0 & 0 & 0 \\
\hline Islet & 4.83 & 0.01 & 0 \\
\hline Perforation & 144.96 & 0.30 & 0.02 \\
\hline
\end{tabular}

\subsection{Evaluation of Landscape Connectivity}

Conefor software was used to evaluate the landscape connectivity of patches in the core areas in the study area through the IIC, $P C$, and $d_{P C}$ landscape index, and the 10 patches in the core areas with a $d_{P C}$ value greater than 5 were regarded as the source of biological species development and proliferation (Table 3).

\subsection{Ecological Corridor Construction Based on the MCR Model}

Combined with the analysis and evaluation results of MSPA and landscape connectivity, 10 sources of ecological processes were selected according to the $d_{P C}$ value of patches in the core area, and resistance factors such as elevation, slope, land type, distance from railway, and distance from other roads were selected to construct the comprehensive resistance surface through the "comprehensive weighted index and method" (Figure 4). 
Table 3. Ranking of the importance of core area based on landscape connectivity.

\begin{tabular}{ccc}
\hline Order & No. & $\boldsymbol{d}_{\boldsymbol{P C}}$ \\
\hline 1 & 21 & 4.068 \\
\hline 2 & 22 & 4.065 \\
\hline 3 & 10 & 4.048 \\
\hline 4 & 23 & 4.041 \\
\hline 5 & 7 & 4.028 \\
\hline 6 & 20 & 4.027 \\
\hline 7 & 8 & 4.023 \\
\hline 8 & 24 & 4.018 \\
\hline 9 & 6 & 3.984 \\
\hline 10 & 5 & 3.980 \\
\hline
\end{tabular}

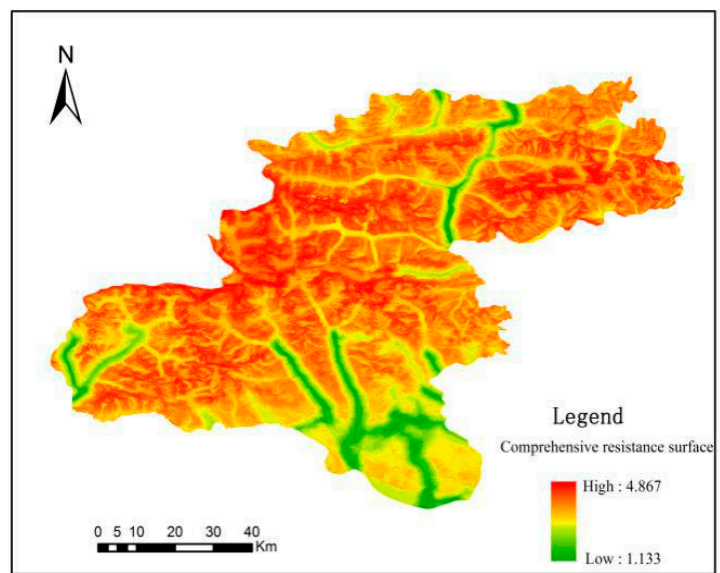

(a)

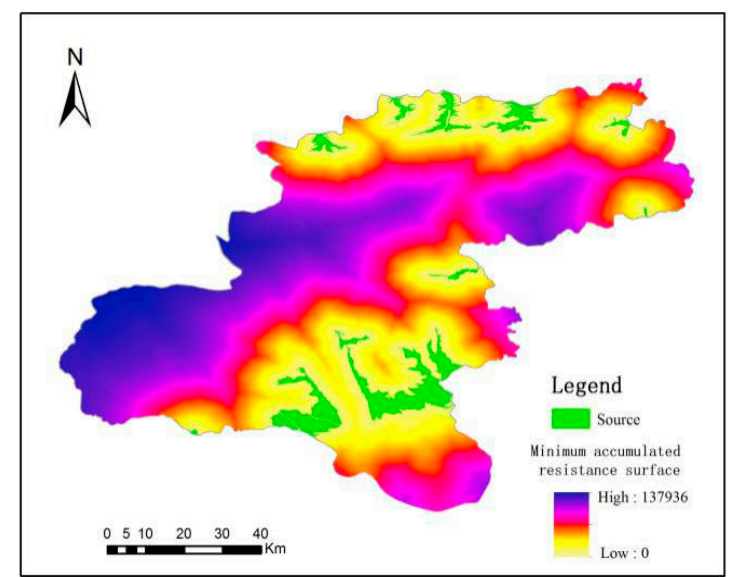

(b)

Figure 4. (a) Comprehensive resistance surface and (b) minimal cumulative resistance surface. Drawn by the first author.

The higher the score, the greater the resistance of the diffusion process of biological species (Table 4). A grid unit size of $30 \times 30 \mathrm{~m}$ was adopted, and the integrated resistance surface was obtained by a grid calculator as the cost data of the MCR model.

Then, based on ArcGIS software platform and the cost distance module in distance, the minimum cumulative cost distance between each pixel and the nearest unit on the cost surface was calculated using the ecological source and comprehensive resistance surface. Using the cost path module in distance, 45 potential corridors in the study area were generated (Figure 5).

Using the gravity model, the interaction matrix between patches of 10 ecological source areas was calculated (Table 5). The interaction intensity between patches of different source areas was evaluated in a quantitative way so that the relative importance of potential corridors in the region could be judged more scientifically. 
Table 4. Score and weight of resistance factors.

\begin{tabular}{|c|c|c|c|}
\hline Resistance Factor & Classification Index & Evaluation & Weight \\
\hline \multirow{5}{*}{ Elevation } & $>2500$ & 1 & \multirow{5}{*}{0.179} \\
\hline & $2500-3500$ & 2 & \\
\hline & $3500-4500$ & 3 & \\
\hline & $4500-5500$ & 4 & \\
\hline & $>5500$ & 5 & \\
\hline \multirow{5}{*}{ Gradient } & $0-10$ & 1 & \multirow{5}{*}{0.275} \\
\hline & $10-30$ & 2 & \\
\hline & $30-50$ & 3 & \\
\hline & $50-70$ & 4 & \\
\hline & $>70$ & 5 & \\
\hline \multirow{5}{*}{ Land Use } & woodland & 1 & \multirow{5}{*}{0.133} \\
\hline & $\begin{array}{l}\text { Cultivated land, } \\
\text { grassland }\end{array}$ & 2 & \\
\hline & other land & 3 & \\
\hline & waters & 4 & \\
\hline & artificial area & 5 & \\
\hline \multirow{5}{*}{ Distance from drainage } & $0-500$ & 1 & \multirow{5}{*}{0.159} \\
\hline & $500-1000$ & 2 & \\
\hline & $1000-1500$ & 3 & \\
\hline & $1500-2000$ & 4 & \\
\hline & $>2000$ & 5 & \\
\hline \multirow{5}{*}{ Distance from roads } & $0-500$ & 1 & \multirow{5}{*}{0.254} \\
\hline & $500-1000$ & 2 & \\
\hline & $1000-1500$ & 3 & \\
\hline & $1500-2000$ & 4 & \\
\hline & $>2000$ & 5 & \\
\hline
\end{tabular}

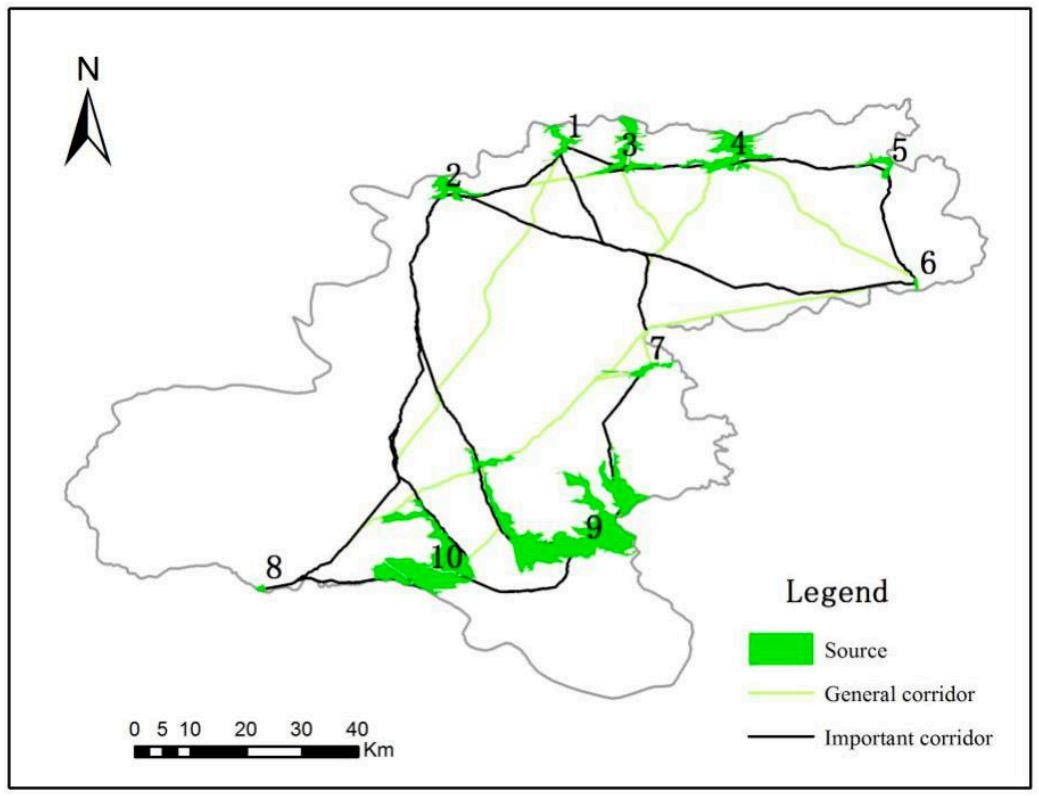

Figure 5. Potential ecological corridors of the study area. Drawn by the first author. 
Table 5. Interaction matrix based on the gravity model.

\begin{tabular}{|c|c|c|c|c|c|c|c|c|c|c|}
\hline & 1 & 2 & 3 & 4 & 5 & 6 & 7 & 8 & 9 & 10 \\
\hline 1 & - & 5.31 & 31.03 & 5.67 & 0.94 & 0.41 & 1.6 & 0.1 & 0.35 & 0.23 \\
\hline 2 & & - & 4.37 & 1.99 & 0.51 & 0.28 & 1.2 & 413.13 & 33.12 & 0.28 \\
\hline 3 & & & - & 18.84 & 1.69 & 0.64 & 2.59 & 0.13 & 0.48 & 0.31 \\
\hline 4 & & & & - & 4.37 & 1.19 & 3.93 & 0.15 & 0.61 & 0.38 \\
\hline 5 & & & & & - & 2.21 & 0.83 & 0.07 & 0.23 & 0.15 \\
\hline 6 & & & & & & - & 0.7 & 0.06 & 0.19 & 0.13 \\
\hline 7 & & & & & & & - & 2.76 & 211.83 & 0.84 \\
\hline 8 & & & & & & & & - & 0.70 & 1.85 \\
\hline 9 & & & & & & & & & - & 5.42 \\
\hline 10 & & & & & & & & & & - \\
\hline
\end{tabular}

\section{Discussion}

\subsection{Analysis of Landscape Pattern Based on MSPA Method}

According to Figure 2 and Table 2, the core area in the study area is about 40721.71 ha, accounting for $84.27 \%$ of the total area of woodland. It is mainly concentrated in the northern and southern regions of the study area, while the central region is scarce, leading to poor landscape connectivity in the southern and northern regions of the study area, which is not conductive to the diffusion and communication of organisms and substances between patches in the core area. The area of connection bridge is about 62.81 ha, accounting for $0.13 \%$ of the total area of woodland, which is of great significance for the communication of matter and energy between core patches in the study area. As the transition area between the core area and the peripheral nongreen landscape area, the marginal area accounts for about $14.42 \%$ of the total area of the forest land and has the edge effect, which can reduce the impact caused by the interference of external factors. Islets were mainly scattered in the central and marginal areas of the study area, accounting for about $0.01 \%$ of the total area of woodland. The branch lines with certain connectivity in the core patches and the perforation in the patches accounted for $0.87 \%$ and $0.30 \%$ of the total forest area, respectively.

\subsection{Analysis of Landscape Connectivity}

It can be seen from Table 3 and Figure 3 that 10 sources of ecological processes were selected according to the $d_{P C}$ value of the core area, showing that the core patches with good connectivity are mainly distributed in the northern part of the study area. Compared with the central and southern areas, the habitat patches in the northern part are more suitable for the migration of biological species and the exchange of material and energy, which can better provide habitats and habitats for species. However, the integral connectivity in the study area is very poor, with a serious fault between the south and the north. On the whole, it is very necessary to construct stepping-stone green patches in the central and southern regions, so as to maintain the sound development of the ecological service function and the balance of the ecosystem in the study area, which needs to be protected.

\subsection{Analysis of Ecological Corridors Construction}

As can be seen from Figure 4 and Table 5, the interaction matrix between patches generated based on the gravity model can measure the strength of the relationship between patches by quantization, and then the importance of corridors between patches to the ecosystem in the region can be inferred. For example, the interaction between patches 4 and 5 was the strongest, and so was the association between these two patches; it is more likely that the biological species can overcome the resistance to migrate, and the communication and transmission of material and energy between the two plaques are simpler; therefore, the protection of the corridor should be strengthened to avoid damage caused by the expansion of construction land. 
Due to the farthest distance between patches 6 and 8, communication is least likely between these two patches. Considering the weak connection between the southern and northern regions of the study area, it is necessary to build a bridge for material and energy exchange between the northern and southern regions to ensure the integral connectivity of the study area. Therefore, the corridor between patches 6 and 8 is particularly important, the protection of which is beneficial to the species migration between the north and south regions of the study area.

The results show that the MSPA method and MCR model can be organically integrated, which is a new idea of ecological corridor planning in the world natural heritage area and can provide reference for the construction of an ecological network. When using the MSPA method to analyze the landscape, the research scale is relatively sensitive, and the change of resolution of the grid cell usually influences the analysis results of MSPA. Choosing the appropriate scale is an important content of MSPA research. The area studied in this paper is the Tomur World Natural Heritage area, which has a small area and a large particle size, will lead to the loss of some small patches with good connectivity. Therefore, the particle size is set as $30 \mathrm{~m}$. In addition, the setting of ecological resistance value has a great influence on the construction of an ecological network, but there is no accepted standard at present. Due to the lack of detailed ecological information in the study area, the construction of ecological corridors has not specifically considered the living characteristics of a species. This paper attempts to improve the connectivity of the habitat patches in the study area and the ecological environment quality and avoid the ecological system damage caused by urban expansion, so as to realize the organic unity of protection and growth. Finally, when Conefor software is used to calculate landscape connectivity, the connectivity distance threshold is set as $500 \mathrm{~m}$, and the connectivity probability is 0.5 . The setting of the threshold will have a certain impact on the calculation of connectivity index, and more detailed research is needed on the scientific nature of the threshold size.

\section{Conclusions}

Taking Tomur as the research area and from the perspective of ecological landscape planning, this paper establishes important ecological corridors based on the MSPA method and MCR model to protect the living environment of ecological patches and species. The MSPA method was adopted to analyze the woodland landscape in the study area. In the selection of an ecological source, not only the value of ecological services was considered, but the structural connection was also emphasized. The landscape types of the core areas with important ecological significance were identified by morphological principles. The importance of the core patches in the study area was quantitatively evaluated by $P C$ and IIC landscape indexes, which changed the subjectivity of the previous artificial ecological source selection to some extent and improved the selection method of the ecological source. Based on the MCR model, multiple resistance factors were comprehensively considered, and the ecological resistance surface was constructed by the comprehensive index weighting method to generate the least resistance corridor between the ecological sources in the study area. According to the strength of interaction between the sources, the Gravity model was used to evaluate the importance of the corridor, and the priority protection order of the corridor was quantitatively analyzed. As an important species location and habitat, the core patch is an important functional node for constructing an ecological network and plays an important role in species migration and diffusion. On the basis of protecting the natural base, reasonable corridor planning suggestions are put forward: (1) The existing corridors, especially the important corridors, should be protected, and the gaps should be repaired to enhance the connectivity of corridors; (2) In areas where there is a lack of connectivity between the relatively important core areas, an appropriate connection bridge corridor or island corridor should be added according to site conditions to promote material exchange and energy flow between the core areas and enhance species diversity. 
Author Contributions: All authors contributed to designing the research, writing and revising the manuscript, as well as analyzing the data. All authors have read and agreed to the published version of the manuscript.

Funding: This study was supported by the National Key Research and Development Program of China (No. 2016YFC0503301).

Acknowledgments: This study was supported by the National Key Research and Development Program of China (No. 2016YFC0503301). Special thanks are owed to the editors and anonymous reviewers who gave constructive suggestions and comments for improving this article.

Conflicts of Interest: The authors declare no conflict of interest.

\section{References}

1. Guo, S.; Saito, K.; Yin, W.; Su, C. Landscape connectivity as a tool in green space evaluation and optimization of the haidan district, Beijing. Sustainability 2018, 10, 1979. [CrossRef]

2. Jiang, P.; Cheng, L.; Li, M.; Zhao, R.; Huang, Q. Analysis of landscape fragmentation processes and driving forces in wetlands in arid areas: A case study of the middle reaches of the Heihe River, China. Ecol. Indic. 2014, 46, 240-252. [CrossRef]

3. Saura, S.; Estreguil, C.; Mouton, C.; Rodríguez-Freire, M. Network analysis to assess landscape connectivity trends: application to European forests (1990-2000). Ecol. Indic. 2011, 11, 407-416. [CrossRef]

4. Richter, B.; Behnisch, M. Integrated evaluation framework for environmental planning in the context of compact green cities. Ecol. Indic. 2019, 96, 38-53. [CrossRef]

5. Li, S.; Yang, B. Introducing a new method for assessing spatially explicit processes of landscape fragmentation. Ecol. Indic. 2015, 56, 116-124. [CrossRef]

6. Hong, W.; Guo, R.; Su, M.; Tang, H.; Chen, L.; Hu, W. Sensitivity evaluation and land-use control of urban ecological corridors: A case study of Shenzhen, China. Land Use Policy 2017, 62, 316-325. [CrossRef]

7. Liang, J.; He, X.; Zeng, G.; Zhong, M.; Gao, X.; Li, X.; Li, X.; Wu, H.; Feng, C.; Xing, W. Integrating priority areas and ecological corridors into national network for conservation planning in China. ScTEn 2018, 626, 22-29. [CrossRef]

8. LaPoint, S.; Gallery, P.; Wikelski, M.; Kays, R. Animal behavior, cost-based corridor models, and real corridors. Landsc. Ecol. 2013, 28, 1615-1630. [CrossRef]

9. Kong, F.; Yin, H.; Nakagoshi, N.; Zong, Y. Urban green space network development for biodiversity conservation: Identification based on graph theory and gravity modeling. Landsc. Urban Plan. 2010, 95, 16-27. [CrossRef]

10. Clergeau, P.; Burel, F. The role of spatio-temporal patch connectivity at the landscape level: an example in a bird distribution. Landsc. Urban Plan. 1997, 38, 37-43. [CrossRef]

11. Lookingbill, T.R.; Elmore, A.J.; Engelhardt, K.A.; Churchill, J.B.; Gates, J.E.; Johnson, J.B. Influence of wetland networks on bat activity in mixed-use landscapes. Biol. Conserv. 2010, 143, 974-983. [CrossRef]

12. Bunce, R.G.H.; Barr, C.J.; Clarke, R.T.; Howard, D.C.; Lane, A.M. Land classification for strategic ecological survey. J. Environ. Manag. 1996, 47,37-60. [CrossRef]

13. Adriaensen, F.; Chardon, J.; De Blust, G.; Swinnen, E.; Villalba, S.; Gulinck, H.; Matthysen, E. The application of 'least-cost'modelling as a functional landscape model. Landsc. Urban Plan. 2003, 64, 233-247. [CrossRef]

14. Saura, S.; Vogt, P.; Velázquez, J.; Hernando, A.; Tejera, R. Key structural forest connectors can be identified by combining landscape spatial pattern and network analyses. For. Ecol. Manag. 2011, 262, 150-160. [CrossRef]

15. Blaschke, T. Object based image analysis for remote sensing. ISPRS J. Photogramm. Remote Sens. 2010, 65, 2-16. [CrossRef]

16. Mann, D.; Agrawal, G.; Joshi, P. Spatio-temporal forest cover dynamics along road networks in the Central Himalaya. Ecol. Eng. 2019, 127, 383-393. [CrossRef]

17. Van Langevelde, F. Modelling the negative effects of landscape fragmentation on habitat selection. Ecol. Inform. 2015, 30, 271-276. [CrossRef]

18. Pascual-Hortal, L.; Saura, S. Comparison and development of new graph-based landscape connectivity indices: towards the priorization of habitat patches and corridors for conservation. Landsc. Ecol. 2006, 21, 959-967. [CrossRef] 
19. Zang, S.-Y.; Yuan, H.; Ning, J. The landscape ecological assessment and planning in the control watershed by reservoir of erlong mountain. Chin. Geogr. Sci. 2002, 12, 176-181. [CrossRef]

20. Ramiadantsoa, T.; Ovaskainen, O.; Rybicki, J.; Hanski, I. Large-scale habitat corridors for biodiversity conservation: A forest corridor in Madagascar. PLoS ONE 2015, 10, e0132126. [CrossRef]

21. Dennis, R.L.; Dapporto, L.; Dover, J.W.; Shreeve, T.G. Corridors and barriers in biodiversity conservation: a novel resource-based habitat perspective for butterflies. Biodivers. Conserv. 2013, 22, 2709-2734. [CrossRef]

22. Hüse, B.; Szabó, S.; Deák, B.; Tóthmérész, B. Mapping an ecological network of green habitat patches and their role in maintaining urban biodiversity in and around Debrecen city (Eastern Hungary). Land Use Policy 2016, 57, 574-581. [CrossRef]

23. Govindan, K.; Loisi, R.V.; Roma, R. Greenways for rural sustainable development: An integration between geographic information systems and group analytic hierarchy process. Land use policy 2016, 50, 429-440.

24. Bryant, M.M. Urban landscape conservation and the role of ecological greenways at local and metropolitan scales. Landsc. Urban Plan. 2006, 76, 23-44. [CrossRef]

25. Gulickx, M.; Verburg, P.; Stoorvogel, J.; Kok, K.; Veldkamp, A. Mapping landscape services: a case study in a multifunctional rural landscape in The Netherlands. Ecol. Indic. 2013, 24, 273-283. [CrossRef]

26. Leitao, A.B.; Ahern, J. Applying landscape ecological concepts and metrics in sustainable landscape planning. Landsc. Urban Plan. 2002, 59, 65-93. [CrossRef]

27. Pino, J.; Marull, J. Ecological networks: are they enough for connectivity conservation? A case study in the Barcelona Metropolitan Region (NE Spain). Land Use Policy 2012, 29, 684-690. [CrossRef]

28. Bodin, Ö.; Saura, S. Ranking individual habitat patches as connectivity providers: integrating network analysis and patch removal experiments. Ecol. Model. 2010, 221, 2393-2405. [CrossRef]

29. Visconti, P.; Elkin, C. Using connectivity metrics in conservation planning-When does habitat quality matter? Divers. Distrib. 2009, 15, 602-612. [CrossRef]

30. Moilanen, A.; Hanski, I. On the use of connectivity measures in spatial ecology. Oikos 2001, 95, 147-151. [CrossRef]

31. Du, X.; Wang, Z. Optimizing monitoring locations using a combination of GIS and fuzzy multi criteria decision analysis, a case study from the Tomur World Natural Heritage site. J. Nat. Conserv. 2018, 43, 67-74. [CrossRef]

32. Hui, S.; Zhaoping, Y.; Fang, H. Assessment and analysis of eco-environment vulnerability in Tomur region of natural heritage site. Arid Land Geogr. 2013, 36, 318-328.

33. Vanbelle, S.; Albert, A. A note on the linearly weighted kappa coefficient for ordinal scales. Stat. Methodol. 2009, 6, 157-163. [CrossRef]

34. Vogt, P.; Riitters, K.H.; Estreguil, C.; Kozak, J.; Wade, T.G.; Wickham, J.D. Mapping spatial patterns with morphological image processing. Landsc. Ecol. 2007, 22, 171-177. [CrossRef]

35. Saura, S.; Pascual-Hortal, L. A new habitat availability index to integrate connectivity in landscape conservation planning: comparison with existing indices and application to a case study. Landsc. Urban Plan. 2007, 83, 91-103. [CrossRef]

36. Tannier, C.; Bourgeois, M.; Houot, H.; Foltête, J.-C. Impact of urban developments on the functional connectivity of forested habitats: a joint contribution of advanced urban models and landscape graphs. Land Use Policy 2016, 52, 76-91. [CrossRef]

37. Zetterberg, A.; Mörtberg, U.M.; Balfors, B. Making graph theory operational for landscape ecological assessments, planning, and design. Landsc. Urban Plan. 2010, 95, 181-191. [CrossRef]

38. Vogt, P.; European Commission. User Guide of GuidosToolbox. 2018. Available online: https://ies-ows.jrc.ec. europa.eu/gtb/GTB/GuidosToolbox_Manual.pdf (accessed on 23 October 2019).

39. Sun, J.; Southworth, J. Indicating structural connectivity in Amazonian rainforests from 1986 to 2010 using morphological image processing analysis. IJRS 2013, 34, 5187-5200. [CrossRef]

40. Cook, E.A. Landscape structure indices for assessing urban ecological networks. Landsc. Urban Plan. 2002, 58, 269-280. [CrossRef]

41. Carlier, J.; Moran, J. Landscape typology and ecological connectivity assessment to inform Greenway design. ScTEn 2019, 651, 3241-3252. [CrossRef] 
42. De Groot, R.S.; Alkemade, R.; Braat, L.; Hein, L.; Willemen, L. Challenges in integrating the concept of ecosystem services and values in landscape planning, management and decision making. Ecol. Complex. 2010, 7, 260-272. [CrossRef]

43. Hernando, A.; Velázquez, J.; Valbuena, R.; Legrand, M.; García-Abril, A. Influence of the resolution of forest cover maps in evaluating fragmentation and connectivity to assess habitat conservation status. Ecol. Indic. 2017, 79, 295-302. [CrossRef]

44. Zhang, L.; Wang, H. Planning an ecological network of Xiamen Island (China) using landscape metrics and network analysis. Landsc. Urban Plan. 2006, 78, 449-456. [CrossRef]

(C) 2020 by the authors. Licensee MDPI, Basel, Switzerland. This article is an open access article distributed under the terms and conditions of the Creative Commons Attribution (CC BY) license (http://creativecommons.org/licenses/by/4.0/). 